\title{
Sinop, Ordu ve Samsun İllerinin Sıcaklık Verilerinde Trend Analizi
}

\author{
Trend Analyses of Temperature Data of Sinop, Ordu and Samsun Provinces
}

\author{
Aslı ÜLKE*1,a ${ }^{\text {Tuğba ÖZKOCA }}{ }^{2, b}$

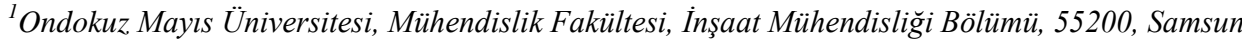 \\ ${ }^{2}$ DSİ 13. Bölge Müdürlüğü, 07080, Antalya
}

• Geliş tarihi / Received: 11.11.2017 • Düzeltilerek geliş tarihi / Received in revised form: 08.05.2018 • Kabul tarihi / Accepted: 22.05 .2018

\section{$\ddot{O} z$}

Atmosferdeki sera gazı birikimlerinin artışına bağlı olarak iklim değişikliğinin, Türkiye'de neden olabileceği çevresel etkilerin en önemli sonuçları kuraklık ve taşkın olaylarının sıklığının ve şiddetinin artmasıdır. İklim değişikliği ile ilgili çalışmalar içerisinde sıcaklık parametreleri üzerinde yapılan analizler önemli bir yere sahiptir. Bu çalışmada, Orta Karadeniz Bölgesi kıyı şeridinde bulunan Sinop, Ordu ve Samsun illerinin sıcaklık verileri analiz edilmiştir. Kullanılan veri setleri Meteoroloji Genel Müdürlüğü'nden temin edilmiş̧ir. Verilerin zaman içerisindeki değişimlerinin ortaya konulması için Mann-Kendall Trend Testi ve Sen'in Trend Eğim Testi uygulanmıştır. Sonuçlar, bölgede beklendiği gibi sıcaklığın genellikle artış trendine sahip olduğunu göstermiştir.

Anahtar kelimeler: Karadeniz Bölgesi, Küresel İklim Değişikliği, Mann-Kendall Testi, Sen’in Eğim Testi, Trend Analizi

\begin{abstract}
Of climate change due to increases in greenhouse gas concentrations in the atmosphere, the most important results of the environmental impact in Turkey may cause an increased incidence of droughts and floods. Among the studies pertaining to climate change, the analysis on the parameters of temperature has an important place. In this study, temperature data of Sinop, Ordu and Samsun cities which located in coastal side of the Middle Black Sea Region were analyzed. Used data sets were provided from Turkish State Meteorological Service. Mann-Kendall Trend Test and Sen's Slope Test were performed to data sets to discover how data changes within time. . The results unsurprisingly show that the temperature has mostly positive trend in the region.
\end{abstract}

Keywords: Black sea Region, Global Climate Change, Mann-Kendall Analysis, Sen's Slope Test, Trend Analysis

\footnotetext{
*a Aslı ÜLKE; asli.ulke@omu.edu.tr; Tel: (0362) 3121919 (dahili: 1101); orcid.org/0000-0002-9676-8377

b orcid.org/0000-0002-9959-478X
} 


\section{Giriş}

20. yüzyılda, uygarlığın hızlı gelişimiyle birlikte doğal kaynaklar insanlar tarafindan hizla tüketilmeye başlanmıştır. Sanayileşme, araç kullanımı ve evlerde fosil yakıt kullanımı giderek artmıştır. Fosil yakıt kullanımı da atmosfere bol miktarda sera gazı salınmasına neden olmuştur. Artan sera gazı miktarı iklimi etkilemektedir ve iklimde hissedilebilir değişiklikler meydana gelmeye başlamıştır. İnsan etkisi ile meydana gelmeye başlayan iklim değişikliğinin yanı sıra doğal değişkenlikler de iklimi etkilemektedir. $\mathrm{Bu}$ doğal değişkenlikler iç ve dış süreç olarak ayrıldığında; iç süreçler, genellikle atmosfer, okyanuslar, krayosfer, biyosfer ve litosfer arasındaki karşılıklı etkileşimin çeşitli birleşimlerini içermektedir. Dış süreçler ise, güneş radyasyonu ve dünyanın yörünge değişimleri, kutupların yer değiştirmesi, kıtaların kayması ve yükselmesi, dağ oluşumu, deniz seviyesi değişimleri gibi klimatolojik, atmosferin kütlesi ve kompozisyonu gibi meteorolojik, volkanik aktivite ve stratosferik aerosollerin üretimi gibi jeomorfolojik etmenlerden oluşmaktadır (Türkeş, 1989).

İnsanlığın son yüzyıl içinde yaptığı tahribatın bir sonucu olarak havanın da bileşimi önemli ölçüde bozulmuştur. Artan şehirleşme, özellikle sanayi ve yerleşim bölgelerinden çıkan sera gazları nedeniyle çevre ve atmosfer büyük ölçüde kirlenmekte ve küresel ölçekte havanın 1sınma eğilimi de giderek artmaktadır (Kadığlu, 2008). Buna dayanarak insanın iklimi, iklimin de insanı etkilediği ortadadır. Ülkemizde kuraklığın yakın bir zamanda bugünkünden çok daha fazla hissedilebileceği açıktır. $\mathrm{Bu}$ nedenle, suyun öneminin artacağı göz önünde bulundurularak, ileriki yıllarda, suyun yönetimine, kurakl1k planlarına, suyun yeniden kullanımıyla ilgili sistemlerin geliştirilmesi ve sulama tekniklerinin iyileştirilmesi çabaları yoğunluk kazanmalıdır.

Ülkemiz için su, enerji ve tarım açısından son derece önemlidir. Su yapılarının amaçlarına uygun faaliyet gösterebilmesi ise ancak yeterli miktarda yağışın düşmesi ile mümkün olmaktadır. Buharlaşmanın, küresel ısınma ile artacağı ve ülkemizde daha şiddetli ve uzun süreli kuraklıkların görüleceği tahmin edilmektedir. $\mathrm{Bu}$ nedenle hem su kaynakları, hem de yağışa bağlı olan tarım ve hidroelektrik enerji üretimi büyük oranda etkilenebilmektedir. Hidrolojik döngüdeki değişimler diğer yandan, ani sel olaylarını da tetiklemektedir. Son yıllarda ülkemizde sicaklık, yağış, akış ve deniz seviyesi gibi değişik parametreler üzerinde trend analizi ile ilgili değişik bölgeleri kapsayan çalışmalar gittikçe artmaktadır (Türkeş vd. 1995; 1996; Kadığlu, 1997; Kahya ve Kalayc1, 2004; Partal ve Kahya, 2006; Toros, 2012; Erlat ve Türkeş, 2013). Türkeş vd., (2002), yaptıkları çalışmada kış ve ilkbahar ortalama sıcaklıklarının özellikle Türkiye'nin güney bölgelerinde artma eğiliminde olduğunu tespit etmişlerdir.

Karadeniz Bölgesinde de benzer çalışmalar gerçekleştirilmiştir, kısaca özetlenecek olursa; Tecer vd., (2004), Rize ölçüm istasyonundan aldıkları 1975-2001 yıllarına ait sıcaklık ve yağış verilerine çeşitli istatistiksel analiz yöntemleri uygulayarak iklim değişimini yerel olarak ele almışlardır. Analiz sonucunda, ortalama yıllık ve ortalama maksimum yıllık sıcaklıklarda artış saptarken, Rize yağışlarının da daha yağışlı bir iklime doğru eğilim gösterdiğini tespit etmişlerdir. Okutan vd., (2004), iklim değişikliklerinin, özellikle Çayeli ve yöresindeki yağışlar üzerindeki etkilerine bağlı olarak, yörede gelişen seller ve heyelanların incelenmesini amaçladıkları çalışmalarında Kuzeydoğu Anadolu'da sıcaklıkların zaman içinde düzenli olarak arttığını belirlemişlerdir. Kahya vd., (2004), Türkiye'deki akım değerlerinin trend analizi üzerine yaptıkları çalışmada 31 y1llık veri seti ile Sen's T test, Sperman Rho Testi ve Mann-Kendall testini kullanarak trend analizi çalışması yapmışlardır. Yaptıkları çalışma neticesinde Türkiye'nin batısında $0,05^{\circ} \mathrm{C}^{\prime}$ lik bir azalış trendi, doğusunda ise herhangi bir trendin olmadığını vurgulamışlardır. Ayrıca yaptıkları çalışmada Yeşilırmak'ın kuzeyinde bir pozitif trendin var olduğunu belirtmişlerdir. Şensoy vd., (2005), Türkiye'de sicaklıkların artma eğiliminde olduğunu, günlük sıcaklık genişliği ile birlikte donlu ve buzlu günlerin sayısinda azalma olduğunun belirtmiştir. Aynı zamanda serin geceler sayısı azalırken, sıcak geceler sayısının artış gösterdiğini, hem maksimum hem de minimum sıcaklıkların arttığını vurgulamıştır. Ceylan ve Kömüşcü (2007), Meteorolojik Karakterli Doğal Afetlerin Uzun Yillar ve Mevsimsel Dağılımlarını ortaya koymak amacıyla yaptıkları çalışmada, 1940-2006 yıllarını esas alarak 2000'li yıllardan itibaren doğal afetlerin sayısında artış eğilimi olduğunu belirtmişlerdir. $\mathrm{Bu}$ tür olayların özellikle Karadeniz ve İç Anadolu Bölgelerinde ön plana çıktığını belirtmişlerdir. Türkeş (2007), tüm dünyadaki ortalama sıcaklıklarda bir artışın olduğunu, 19962005 döneminde küresel ortalama sicaklıklarda $0,74{ }^{\circ} \mathrm{C}^{\prime}$ lik artış trendinin olduğu sonucunu elde etmiştir. Cosun ve Karabulut (2009), 
Kahramanmaraş'ta ortalama, minimum ve maksimum sıcaklıkları için trend analizi çalışması yapmışlardır. Kahramanmaraş ve Elbistan istasyonlarında sıcaklıkta anlamlı bir artışın varlığını olduğunu tespit etmişlerdir. Tecer ve Cerit (2009), 1975-2007 y1lları arasında Rize ilindeki sıcaklık değerlerinin trend analizi üzerine yaptıkları çalışmalarında 33 yıllık periyotta maksimum sıcaklıklarda $1.61{ }^{\circ} \mathrm{C}^{\prime}$ lik bir artışın olduğu, ayrıca yıllık minimum sicaklıklarda ise $0.99{ }^{\circ} \mathrm{C}$ 'lik artış trendinin olduğu sonucunu elde etmişlerdir. Erlat ve Türkeş (2013), Türkiye'nin 2010 yılına kadar olan dönemde yaz günlerinin ve tropikal günlerin sayısının artışına yönelik 97 meteoroloji istasyonu ile yaptıkları çalışmalarında Anadolu'nun kuzeybatısında pozitif bir trendin olduğunun sonucuna varmışlardır. Doğan vd., (2014a), 1950-2006 dönemini ele alarak Türkiye'deki sıcaklık serilerinin trend analizi üzerine yaptıkları çalışmalarında 1992 yı1ı itibariyle trendde bir dönüm noktası olduğunu elde etmişlerdir. Yine Doğan vd., (2014b), elde ettikleri çalışma sonucuna göre Türkiye kıyılarının deniz seviyelerinde belirgin bir artış söz konusudur.

Çalışmada Orta Karadeniz Bölgesi'nde bulunan Sinop, Ordu ve Samsun illerinin sicaklık verileri kullanılarak trend analizi yapılmıştır. Çalışma özellikle bölgede son yıllarda meydana gelen taşkınlarla, sıcaklıktaki değişimlere bir açıklama bulabilmek amacıyla gerçekleştirilmiştir.

\section{Materyal ve Yöntem}

Çalışmada sadece bölgenin kıyı kesimlerinde yer alan Sinop, Ordu ve Samsun illerinin sicaklik verilerin trend analizi çalışılmış, Devlet Meteoroloji Genel Müdürlügü’nün 13 adet istasyonun 1975-2013 y1lları arasındaki ortalama sıcaklık verileri kullanılmıştır (Şekil 1). İstasyonların denizden olan yükseklik, enlem, boylamı Tablo 1'de, istasyonlara ait temel istatistikler ise Tablo 2'de yer almaktadır.

Çalışma bölgesinde kış ayları ortalama sıcaklık değeri $7^{\circ} \mathrm{C}$ ve yaz ayları ortalama sicaklık değeri $22^{\circ} \mathrm{C}^{\prime}$ dir (TUIK, 2012). Bölgede Yeşilırmak ve Kızılırmak nehirleri, bunların kolları ve küçük dereler mevcuttur.

Trend analizinin amac1; uzun dönemlerde toplanan verilerden oluşan zaman serilerinde verinin eğilimini incelemektir. Bu amaçla MannKendall Trend Analizi ve Sen's Trend Eğim Testi en sık kullanılan trend analizi yöntemleridir.

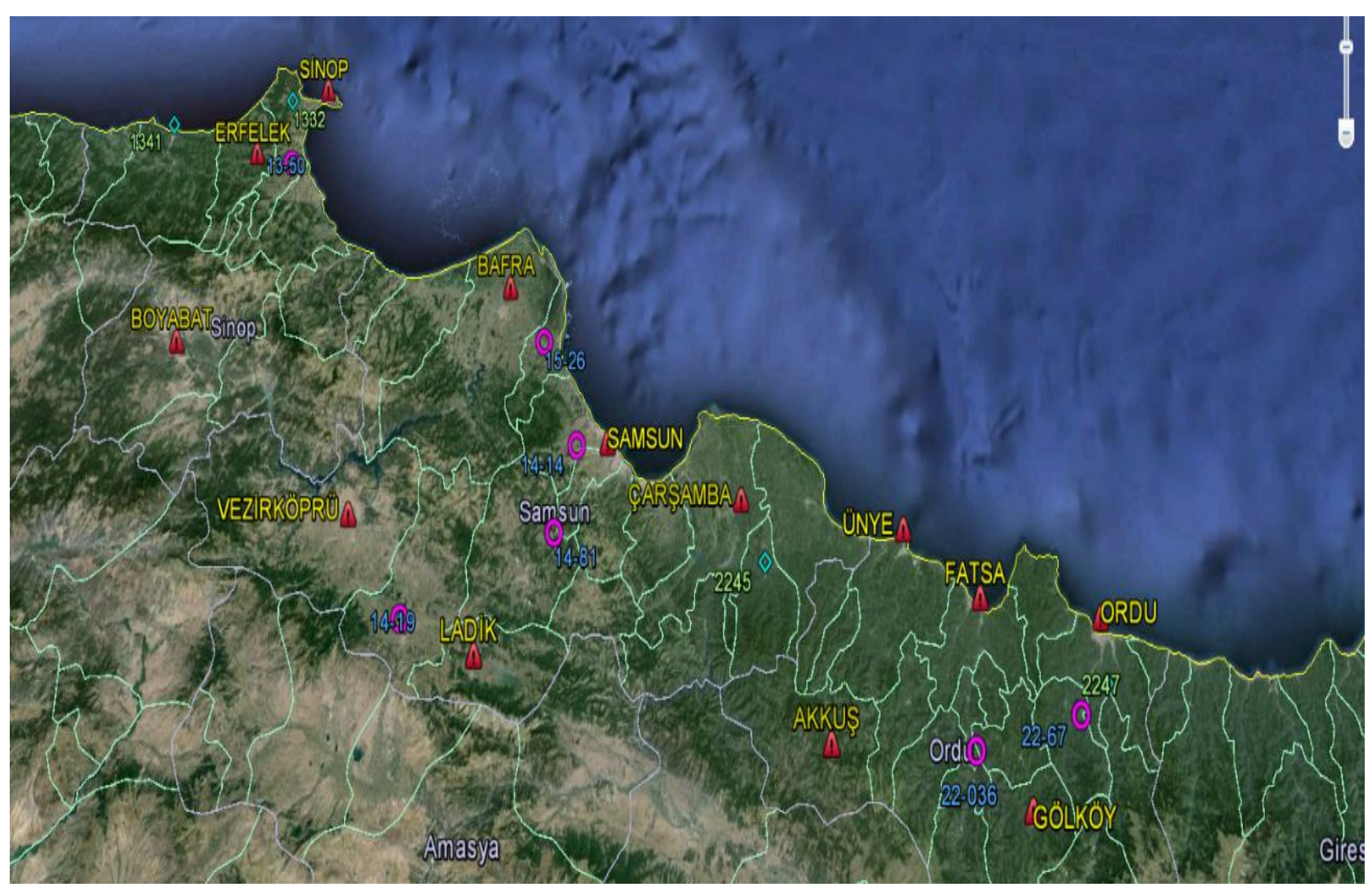

Şekil 1. Bölgenin haritası ve kullanılan istasyonların gösterimi 
Tablo 1. Kullanılan istasyonlara ait bilgiler

\begin{tabular}{|lllll|}
\hline No. & İstasyon Ad 1 & Yükseklik(m) & Enlem & Boylam \\
\hline 1 & Bafra & 20 & $41^{\circ} 35^{\prime} \mathrm{K}$ & $35^{\circ} 56^{\prime} \mathrm{D}$ \\
\hline 2 & Boyabat & 350 & $41^{\circ} 28^{\prime} \mathrm{K}$ & $34^{\circ} 46^{\prime} \mathrm{D}$ \\
\hline 3 & Çarşamba & 35 & $41^{\circ} 11^{\prime} \mathrm{K}$ & $36^{\circ} 45^{\prime} \mathrm{D}$ \\
\hline 4 & Erfelek & 175 & $41^{\circ} 52^{\prime} \mathrm{K}$ & $34^{\circ} 56^{\prime} \mathrm{D}$ \\
\hline 5 & Fatsa & 10 & $41^{\circ} 01^{\prime} \mathrm{K}$ & $37^{\circ} 31^{\prime} \mathrm{D}$ \\
\hline 6 & Gölköy & 925 & $40^{\circ} 41^{\prime} \mathrm{K}$ & $37^{\circ} 37^{\prime} \mathrm{D}$ \\
\hline 7 & Ladik & 950 & $40^{\circ} 55^{\prime} \mathrm{K}$ & $35^{\circ} 54^{\prime} \mathrm{D}$ \\
\hline 8 & Ordu & 4 & $40^{\circ} 59^{\prime} \mathrm{K}$ & $37^{\circ} 54^{\prime} \mathrm{D}$ \\
\hline 9 & Samsun & 4 & $41^{\circ} 17^{\prime} \mathrm{K}$ & $36^{\circ} 18^{\prime} \mathrm{D}$ \\
\hline 10 & Sinop Hvl. & 14 & $42^{\circ} 01^{\prime} \mathrm{K}$ & $35^{\circ} 04^{\prime} \mathrm{D}$ \\
\hline 11 & Sinop & 32 & $42^{\circ} 01^{\prime} \mathrm{K}$ & $35^{\circ} 10^{\prime} \mathrm{D}$ \\
\hline 12 & Ünye & 20 & $41^{\circ} 08^{\prime} \mathrm{K}$ & $37^{\circ} 17^{\prime} \mathrm{D}$ \\
\hline 13 & Vezirköprü & 260 & $41^{\circ} 09^{\prime} \mathrm{K}$ & $35^{\circ} 27^{\prime} \mathrm{D}$ \\
\hline
\end{tabular}

Trend analiz testleri yapıldıktan sonra ele alınan parametrelerin geçmişten günümüze nasıl bir artış veya azalış içinde olduğu, aynı zamanda gelecek yıllarda da eğilimin nasıl olacağı konusu tespit edilmiş olur.

\subsection{Homojenlik Testleri}

Uzun iklim kayıtlarına dayalı iklim değişikliği çalışmalarının ilk aşamasında kaçınılmaz olarak iklim verilerine homojenlik testi uygulanmalıdır. Homojen olmayan bir istasyondaki veriler, ayn bölge içinde komşu gözlemlerle karşılaştırıldığında ortalamadan ani sıçrama farkı ile karşımıza çıkar. Bu tip ani sıçramalar genellikle istasyonun yerlerinin değiştirilmesiyle ilgilidir. Bu çalışmada verilerin homojenliğini kontrol etmede 2 tip test uygulanmıştır. Bununla birlikte gözlem programlarındaki değişiklikler, ölçüm cihazlarının yeniden kalibre edilmesi ya da insan kaynaklı ani çevresel değişiklikler de bunlara neden olurlar (Alexandersson ve Moberg 1997; Doğan vd., 2014b).

\subsubsection{Standart Normal Homojenlik Testi}

Birçok iklimsel ve hidrolojik büyüklügün homojen olup olmadığını belirlenmesinde kullanılan bu yöntem Alexandersson tarafindan 1986 yılında geliştirilmiştir. Esnek ve basit bir kullanıma sahip olan yöntem hidrometeorolojik veri setinin bir noktasını baz alarak ikiye böler ve 1 nolu denklemde $\mathrm{T}(\mathrm{c})$ değerini bulur.

Tablo 2. Kullanılan istasyonlara ait temel istatistikler

\begin{tabular}{|lcccc|}
\hline İstasyon Ad 1 & \multicolumn{1}{c}{$\begin{array}{c}\text { Ortalama } \\
\left({ }^{\circ} \mathrm{C}\right)\end{array}$} & $\begin{array}{c}\text { Maksimum } \\
\left({ }^{\circ} \mathrm{C}\right)\end{array}$ & $\begin{array}{c}\text { Minimum } \\
\left({ }^{\circ} \mathrm{C}\right)\end{array}$ & Std. Sapma \\
\hline Bafra & 13.712 & 15.631 & 12.383 & 0.732 \\
\hline Boyabat & 13.074 & 15.103 & 11.417 & 0.784 \\
\hline Çarşamba & 14.315 & 15.867 & 13.183 & 0.576 \\
\hline Erfelek & 13.350 & 15.423 & 10.217 & 0.984 \\
\hline Fatsa & 14.427 & 16.633 & 13.292 & 0.747 \\
\hline Gölköy & 9.622 & 12.300 & 7.383 & 1.061 \\
\hline Ladik & 9.885 & 12.110 & 8.283 & 0.835 \\
\hline Ordu & 14.381 & 16.600 & 13.100 & 0.743 \\
\hline Samsun & 14.446 & 16.510 & 13.183 & 0.725 \\
\hline Sinop Hvl. & 14.369 & 16.717 & 13.117 & 0.870 \\
\hline Sinop & 14.175 & 16.023 & 13.017 & 0.870 \\
\hline Ünye & 14.322 & 16.433 & 13.092 & 0.758 \\
\hline Vezirköprü & 13.146 & 15.410 & 11.583 & 0.845 \\
\hline
\end{tabular}




$$
T(c)=c \cdot \bar{z}_{1}+(n-c) \cdot c \cdot \bar{z}_{2}{ }^{2}
$$

Burada $\left.\quad \bar{z}_{1}=\sum_{i=1}^{c}\left(y_{i}-\bar{y}\right) / \sigma\right) / c$ ve $\quad \bar{z}_{2}=$ $\left.\sum_{i=1+c}^{n}\left(y_{i}-\bar{y}\right) / \sigma\right) /(n-c)$ 'dir.

Veri setindeki değişim eğer bir "h" noktasında meydana geliyorsa, $\mathrm{c}=\mathrm{h}$ noktasinda $\mathrm{T}(\mathrm{c})$ maksimum değerine ulaşır. $T_{0}$ test istatistiği ise 2 nolu denklemde gösterildiği gibidir. Burada $T_{0}$ test istatistiği Tablo 3'de verilen değerini aşarsa sifir hipotezi reddedilir.

$T_{0}=\max _{1 \leq c \leq n} T(c)$

Tablo 3. $\% 99$ ve $\% 95$ güven seviyesinde veri sayısına bağlı $\mathrm{T}_{0}$ test değerleri

\begin{tabular}{|c|c|c|c|c|c|c|}
\hline $\mathbf{N}$ & $\mathbf{2 0}$ & $\mathbf{3 0}$ & $\mathbf{4 0}$ & $\mathbf{5 0}$ & $\mathbf{7 0}$ & $\mathbf{1 0 0}$ \\
\hline $\mathbf{\% 1}$ & 9.11 & 10.15 & 10.77 & 11.19 & 11.73 & 12.22 \\
\hline $\mathbf{\% 5}$ & 6.95 & 7.65 & 8.10 & 8.45 & 8.80 & 9.15 \\
\hline
\end{tabular}

\subsubsection{Pettit testi}

Pettitt tarafından 1979 yılında geliştirilen ve parametrik olmayan bu yöntem aylık veya yıllık ölçekte veri setindeki değişim noktasını bulabilmeyi hedefler. $\mathrm{Bu}$ testte sifir hipotezi serinin bağımsız ve rastgele dağılımını belirtir. Bununla birlikte alternatif hipotez de ani bir değişim olma durumunu belirtmektedir. Yöntemdeki test istatistiğinin Mann-Whitney istatistiği ile ilişkili olduğu bilinmektedir (Wijngaard vd., 2003). Yöntemde ilk olarak $\mathrm{X}_{1}, \ldots, \mathrm{X}_{\mathrm{n}}$ değerleri $\mathrm{r}_{1}, \ldots, \mathrm{r}_{\mathrm{n}}$ olarak Denklem 3'deki şekliyle sıralanır.

$X_{k}=2 \sum_{i=1}^{k} r_{i}-k(n+1) \quad k=1,2, \ldots, n$

Bulunan $X_{k}$ değerleri grafik olarak çizildikten sonra $X_{k}$ 'nın mutlak maksimum değeri değişim noktasını vermiş olur (Denklem 4).

$X_{E}=\max _{1 \leq k \leq n}\left|X_{k}\right|$

$\mathrm{Bu}$ teste ait kritik değerler Tablo 4'de verilmiştir (Pettitt, 1979). Denklem'ün sonucunda elde edilen değer, Tablo 4'de yer alan kritik değerden daha küçük ise o veri dizisi homojen demektir.

Tablo 4. $\% 99$ ve $\% 95$ güven seviyesinde veri sayısına bağlı XE test değerleri

\begin{tabular}{|c|c|c|c|c|c|c|}
\hline $\mathbf{N}$ & $\mathbf{2 0}$ & $\mathbf{3 0}$ & $\mathbf{4 0}$ & $\mathbf{5 0}$ & $\mathbf{7 0}$ & $\mathbf{1 0 0}$ \\
\hline $\boldsymbol{\% 1}$ & 71 & 133 & 208 & 293 & 488 & 841 \\
\hline $\mathbf{\% 5}$ & 57 & 107 & 167 & 235 & 393 & 677 \\
\hline
\end{tabular}

\subsection{Trend Testleri}

\subsubsection{Mann-Kendall Tend Analizi}

Parametrik olmayan bir test olan Mann-Kendall Trend testinde hedeflenen hidrometeorolojik zaman serilerinde var olabilecek pozitif veya negatif yöndeki gidişlerin istatistiksel önemini belirlemektir (Mann, 1945; Kendall, 1975; Mondal vd., 2012).

$\mathrm{i}=1, \ldots, \mathrm{n}-1$ 'e kadar sıralanmış olan bir xi veri seti ile $j=i+1, \ldots$, n' e kadar sıralanmış olan bir xj veri setini kullanan bu testte sıralanmış her bir rakam xi'yi bir başlangıç noktası gibi kullanarak, diğer sıralanmış veri grubu xj ile Denklem 5'de gösterildiği gibi kıyaslama yapar.

$g n\left(x_{j}-x_{i}\right)=\left\{\begin{array}{r}1 ; x_{j}>x_{i} \\ 0 ; x_{j}=x_{i} \\ -1 ; x_{j}<x_{i}\end{array}\right.$

Denklem 6'da ise Mann-Kendall test istatistiği S'nin hesaplanışı anlatılmaktadır. Denklemde n, yıl olarak veri uzunluğunu temsil eder.

$S=\sum_{i=1}^{n-1} \sum_{j=i+1}^{n} \operatorname{sgn}\left(x_{j}-x_{i}\right)$

$\mathrm{S}$ değeri ise $\mathrm{n} \geq 8$ olduğunda ortalaması (Denklem 7) ve varyansı (Denklem 8) ile yaklaşık olarak normal dağılım gösterir. $\mathrm{n} \geq 30$ durumunda ise $\mathrm{z}$ testi, t-testine yaklaşır.

$E(S)=0$

$\operatorname{Var}(S)=\frac{n(n-1)(2 n+5)-\sum_{i=1}^{p} t_{i}\left(t_{i}-1\right)\left(2 t_{i}+5\right)}{18}$

Denklem 8'de p, veri setindeki bağıl grupların sayılarını, ti değeri de i uzunluğundaki bir seride bağl1 gözlemleri ifade etmektedir. Denklem 8'de 
yer alan toplam terimi sadece veri setinde bağl1 gözlem olduğunda kullanılır.

Standartlaştırılmış Mann-Kendall istatistiği $\mathrm{Z}$ ise Denklem 9'daki gibi hesaplanabilir. Seride gidiş yoktur şeklinde ifade edilen sifir hipotezi (H0) varsayımı altında ortalaması sıfir, varyansı bir olan standart normal dağılım göstermektedir. Popülasyon parametresine genellikle belli bir değer atanır ve bu öne sürülen temel iddia sıfır hipotezidir. $\mathrm{H}_{0}$ ile gösterilir. Mann-Kendall test istatistiği $Z_{\text {tablo,1- } \alpha / 2} \leq \mathrm{Z} \leq \mathrm{Z}_{\text {tablo,1- } \alpha / 2}$ eşitsizliğini sağladığında sıfır hipotezi kabul edilmektedir. Artı ve eksi $Z$ değerleri sırasıyla eğilimlerin artan ya da azalan yönde olduğunu göstermektedir (Mondal vd., 2012).

$$
Z=\left\{\begin{array}{c}
\frac{S-1}{\sqrt{\operatorname{Var}(S)}} ; S>0 \\
0 \quad ; S=0 \\
\frac{S+1}{\sqrt{\operatorname{Var}(S)}} ; S<0
\end{array}\right.
$$

\subsubsection{Sen'in Trend Ĕ̈im Testi}

Sen (1968) tarafindan geliştirilen parametrik olmayan bir testtir. Eğer doğrusal bir gidiş mevcut ise gerçek eğim için veri hatalarından veya ekstrem değerlerden etkilenmeyen, eksik değerlerin bulunduğu kayıtlara uygulanabilen parametrik olmayan bir yöntem kullanılabilir (Yue vd., 1993). Burada veri sayısı n olmak üzere önce $\mathrm{j}$ ve $\mathrm{k}$ zamanlarındaki veriler $\mathrm{xj}$ ve $\mathrm{xk}(\mathrm{j}>\mathrm{k})$ ise;

$N=n(n-1) / 2$

adet olmak üzere Qi parametresi;

$Q_{i}=\left(x_{j}-x_{i}\right) /(j-k),(i=1, \ldots ., N)$

bağıntısı ile hesaplanır. Bu bağıntı yardımı ile tüm $\mathrm{Q}_{\mathrm{i}}$ değerleri küçükten büyüğe doğru sıralanır. Sen yöntemine göre, hesaplanan $\mathrm{N}$ adet $\mathrm{Q}_{i}$ değerlerinin medyanı söz konusu doğrusal gidişin eğimini verir. $\mathrm{N}$ sayısının tek olması durumunda Denklem 12, çift olması durumunda ise Denklem 13 kullanılarak ilgili gözlemlerin birim zamandaki değişimi bulunur. Bu değerin pozitif olması artan yönde, negatif olması ise azalan yönde bir eğilimin olduğunu gösterir.

$Q_{\text {medyan }}=Q_{(N+1) / 2}$
$Q_{\text {medyan }}=\frac{\left|Q_{(N) / 2}+Q_{(N+2) / 2}\right|}{2}$

\section{Bulgular}

\subsection{Homojenlik Testleri Uygulamalart}

İki tip homojenlik testi uygulanmış ve bu testler için kullanılan kritik değerler Tablo 5'de verilmiştir. Bu kritik değerler doğrultusunda hangi istasyonların homojen olup olmadığ 1 Tablo 6'da verilmiştir. Çizelgedeki gri renk homojenliğin olmadığını göstermek amacıyla kullanılmıştır. Buna göre Çarşamba istasyonu dişındaki istasyonların homojen olmadığı görülmektedir. Trendin olup olmadığını belirleyen analiz çalışması sonuçlarında da homojen olmayan istasyonlarda güçlü bir trendin varlığı tespit edilmiştir.

Tablo 5. İstasyonlar için homojenlik testi kritik değer tablosu

\begin{tabular}{|c|c|}
\hline \multicolumn{2}{|c|}{$\begin{array}{c}\text { Kritik Değerler (\%5 Anlamlılık Seviyesi için Kritik } \\
\text { Değerler) }\end{array}$} \\
\hline Standart Normal Homojenlik Testi & Pettitt Test \\
\hline 8.1 & 167 \\
\hline
\end{tabular}

Tablo 6. Verilere uygulanan homojenlik testi sonuçları

\begin{tabular}{|l|c|c|c|}
\hline \multicolumn{5}{|c|}{ Test Sonuçları } \\
\hline İstasyon Adı & SNHT & Pettitt Testi & Sinıf \\
\hline Bafra & 12.57 & 246 & $\begin{array}{c}\text { Sinıf 3 - Oldukça } \\
\text { Şüpheli }\end{array}$ \\
\hline Boyabat & 12.83 & 252 & $\begin{array}{c}\text { Sinıf 3 - Oldukça } \\
\text { Şüpheli }\end{array}$ \\
\hline Çarşamba & 1.67 & 79 & $\begin{array}{c}\text { Sinıf 1 - } \\
\text { Homojen }\end{array}$ \\
\hline Erfelek & 14.42 & 301 & $\begin{array}{c}\text { Sinıf 3 - Oldukça } \\
\text { Şüpheli }\end{array}$ \\
\hline Fatsa & 17.87 & 306 & $\begin{array}{c}\text { Sinıf 3 - Oldukça } \\
\text { Şüpheli }\end{array}$ \\
\hline Gölköy & 25.25 & 366 & $\begin{array}{c}\text { Sinıf 3 - Oldukça } \\
\text { Şüpheli }\end{array}$ \\
\hline Ladik & 16.89 & 298 & $\begin{array}{c}\text { Sinıf 3 - Oldukça } \\
\text { Şüpheli }\end{array}$ \\
\hline Ordu & 18.92 & 316 & $\begin{array}{c}\text { Sinıf 3 - Oldukça } \\
\text { Şüpheli }\end{array}$ \\
\hline Samsun & 17.79 & 304 & $\begin{array}{c}\text { Sinıf 3 - Oldukça } \\
\text { Şüpheli }\end{array}$ \\
\hline $\begin{array}{l}\text { Sinop } \\
\text { Havalimanı }\end{array}$ & 18.68 & 325 & $\begin{array}{c}\text { Sinıf 3 - Oldukça } \\
\text { Şüpheli }\end{array}$ \\
\hline Sinop & 18.08 & 303 & $\begin{array}{c}\text { Sinıf 3 - Oldukça } \\
\text { Şüpheli }\end{array}$ \\
\hline Ünye & 18.51 & 306 & $\begin{array}{c}\text { Sinıf 3 - Oldukça } \\
\text { Şüpheli }\end{array}$ \\
\hline Vezirköprü & 19.868 & 330 & $\begin{array}{c}\text { Sinıf 3 - Oldukça } \\
\text { Şüpheli }\end{array}$ \\
\hline
\end{tabular}




\subsection{Mann-Kendall Trend Analizi Uygulaması}

Sicaklık istasyonlarına Mann-Kendall trend analiz testi uygulanarak elde edilen sonuçlar Tablo 7'de gösterildiği gibidir. Tablo 7'den görüleceği gibi her istasyon için anlamlılık düzeyine göre irdeleme yapılmıştır. Çarşamba istasyonu için trendin varlığından söz edilememektedir. Aksine Bafra, Boyabat, Erfelek, Fatsa, Gölköy, Ladik, Ordu, Samsun, Sinop Havaliman1, Sinop, Ünye, Vezirköprü istasyonlarında artış trendinin olduğu görülmektedir. Elde edilen sonuçlara göre bölge genelinde sicaklık değerlerinde bir artma eğiliminin var olduğu sonucuna varılmıştır.

Tablo 7. Sicaklik verilerine ait Mann-Kendall trend testi

\begin{tabular}{|lll|}
\hline \multicolumn{3}{|c|}{ Mann-Kendall Trend Testi } \\
& Sonuçları \\
$(\boldsymbol{\alpha}=\mathbf{0 . 0 5}, \mathbf{Z}=\mathbf{1 . 9 6})$ & \\
\hline İstasyon Adı & Test Z & Trend \\
\hline Bafra & 2.60 & Artış \\
Boyabat & 2.90 & Artış \\
Çarşamba & 0.30 & - \\
Erfelek & 3.04 & Artış \\
Fatsa & 3.12 & Artış \\
Gölköy & 3.68 & Artş̧ \\
Ladik & 3.68 & Artış \\
Ordu & 4.26 & Artış \\
Samsun & 3.87 & Artış \\
Sinop Hvl. & 4.26 & Artış \\
Sinop & 3.77 & Artış \\
Ünye & 3.65 & Artış \\
Vezirköprü & 3.44 & Artış \\
\hline
\end{tabular}

\subsection{Sen'in Trend Eğim Test Analizi Uygulaması}

Sicaklık istasyonları Sen'in testi metodu ile yapılan trend analizine ait sonuçlara ilişkin bilgiler Tablo 8'de verilmiştir. Burada dört istasyona ait analiz şekilleri verilmektedir. Bunlar Bafra istasyonu (0,0303'lük bir artış) "Şekil 2", en düşük artış eğimi gösteren Çarşamba istasyonu (0,0019'luk artış eğimi) "Şekil 3", en yüksek artış eğimi gösteren Gölköy istasyonu $\left(0,0588^{\prime}\right.$ lik artış eğimi) "Şekil 4" ve Samsun istasyonu (0,0411'lik bir artı̧̧ eğimi) "Şekil 5"dir.

Tüm bu elde edilen değerler Sinop, Ordu ve Samsun kıyı illerinde genel olarak artış eğilimi gözlenmekte olduğunu ve bu artışın Ordu ilinin iç kesimlerinde daha yüksek mertebelere ulaştığını göstermektedir (Özkoca, 2015).
Tablo 8. Sen'in Trend Eğim Testi (1975-2013 periyodu, 39 yıl)

\begin{tabular}{|llr|}
\hline \multicolumn{3}{|c|}{ Sen'in Trend Eğim Test Analizi Sonuçları } \\
\hline İstasyon Adı & $\mathrm{Q}$ & \multicolumn{1}{c|}{$\mathrm{B}$} \\
\hline Bafra & 0.0303 & 13.1379 \\
Boyabat & 0.0306 & 12.5639 \\
Çarşamba & 0.0190 & 14.2444 \\
Erfelek & 0.0343 & 12.8565 \\
Fatsa & 0.0333 & 13.7417 \\
Gölköy & 0.0588 & 8.6475 \\
Ladik & 0.0432 & 9.0438 \\
Ordu & 0.0441 & 13.5556 \\
Samsun & 0.0411 & 13.6331 \\
Sinop Hvl. & 0.0481 & 13.4944 \\
Sinop & 0.0400 & 13.5133 \\
Ünye & 0.0396 & 13.5625 \\
Vezirköprü & 0.0411 & 12.3859 \\
\hline
\end{tabular}

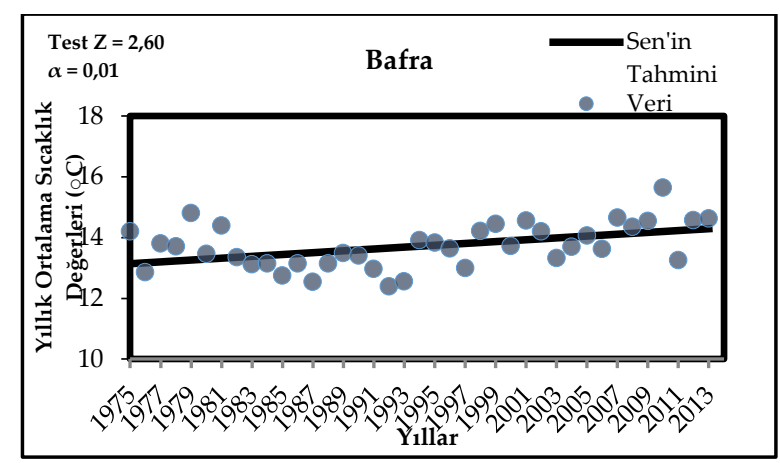

Şekil 2. Bafra İstasyonu Sen'in trend eğim testi analizi

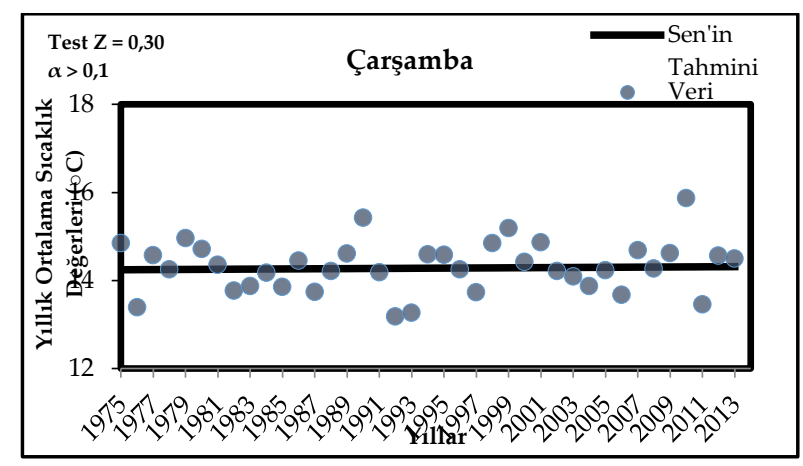

Şekil 3. Çarşamba istasyonu Sen'in trend eğim testi analizi

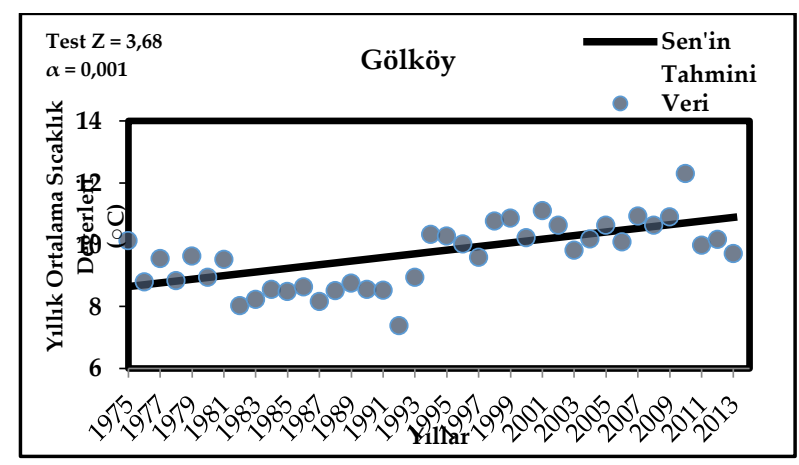

Şekil 4. Gölköy istasyonu Sen'in trend eğim testi analizi 


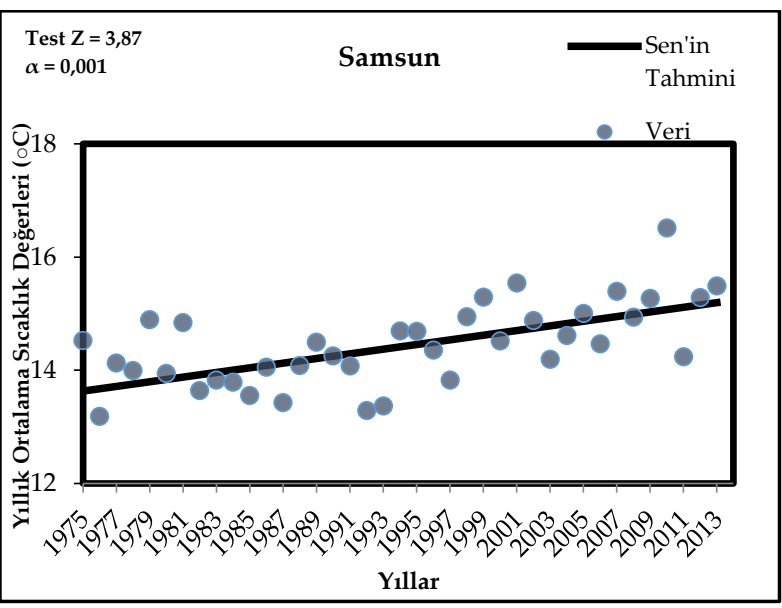

Şekil 5. Samsun istasyonu Sen'in trend eğim testi analizi

\section{Sonuc}

Sicaklık verilerinde Mann-Kendall ve Sen'in Trend Eğim testi sonucunda elde edilen bulguları incelediğimizde Bafra, Boyabat, Erfelek, Fatsa, Gölköy, Ladik, Ordu, Samsun, Sinop Havalimanı, Sinop, Ünye ve Vezirköprü istasyonlarında pozitif yönde anlamlı trendin var olduğu sonucu elde edilmiştir. Çarşamba istasyonunda ise anlamlı bir eğilime rastlanmamıştır. Çarşamba istasyonu için bu şekilde trend olmayışı; verilere uygulanan homojenlik testlerinin sonucuna göre anlamlı bulunmuştur.

Orta Karadeniz Bölgesi kıyı şeridi illerinin trend analizini içeren bu çalışmada sıcaklığın bölge genelinde artış trendinde olduğu görülmektedir. Küresel iklim değişikliğinde artan sıcaklık değerlerinin öncellikle yağışları, dolaylı olarak da akışları ve buharlaşmayı etkilediği ortadadır. İklim değişikliğinin tarıma olan etkisi ise kuraklık şeklinde ortaya çıkmaktadır. Yağış azlığ nedeniyle yeterli sulama yapılamamakta, bu da tarımda verimin düşmesine ve ürün çeşitliliğinin azalmasına sebep olmaktadır. Yaşanan bu kurakl1k sebebiyle bölge ekonomisinin can damarı olan findığın ve pirincin rekoltesinde büyük düşüşler gözlenmiştir. İklim değişimi sebebiyle, kentsel altyapıda problemlere yol açan 5, 10, 15 dakikalık kısa süreli yağışın şiddetinde de bir artış görülmektedir. 2012 yılında il merkezinde yaşanan iki büyük taşkın bunun en iyi göstergesidir. Bölgede zaman zaman içmekullanma ve sulama sularında miktar ve kalite bakımından sıkıntılar gözlenebilmektedir. Son yıllarda yaşanan rejim değişimi sebebiyle Samsun şehir şebeke suyunun miktar ve kalitesinde büyük düşüşler yaşanmıştır.

\section{Kaynaklar}

Alexandersson H. 1986. A Homogeneity Test Applied to Precipitation Data, Journal of Climatology, 6, 661-675.

Alexandersson H. ve Moberg, A. 1997. Homogenization of Swedis temperature data. part I: homogeneity test for linear trends. International Journal of Climatology, 17, 25-34.

Ceylan, A. ve Kömüşçü, A.İ., 2007. Meteorolojik Karakterli Doğal Afetlerin Uzun Yıllar ve Mevsimsel Dağılımları, 1. Türkiye İklim Değişikliği Kongresi, 11-13 Nisan 2007, İTÜ, İstanbul, Türkiye s. 93-104.

Cosun, F., ve Karabulut, M., 2009. Kahramanmaraş'ta Ortalama, Minimum ve Maksimum Sicaklıkların Trend Analizi

Doğan M., Ulke A. ve Cigizoglu, H.K., 2014a. Trend direction changes of Turkish temperature series in the first half of 1990s, Theor. Appl. Clim., vol.121, no:1 2, 23-39.

Doğan M., Cigizoglu, H.K., Şanlı, D.U. ve Ulke A., 2014b. Investigation of sea level anomalies related with NAO along the west coasts of Turkey and their consistency with sea surface temperature trends, Theor. Appl. Clim., vol.121, no: 12, 349-358

Erlat, E. ve Türkeş. M., 2013. Observed changes and trends in number of summer and tropical days and the 2010 hot summer in Turkey, International Journal of Climatology, 33, s.1898-1908.

Helsel D. R. ve Hirsch R. M. 1992. Statistical Methods in Water Resources. Studies in Environmental Science 49, New York, Elsevier

Kadıoğlu, M., 1997. Trends in surface air temperature data over Turkey, International Journal of Climatology, 17, s. 511-520.

Kadığlu, M., 2008. Günümüzden 2100 yılına iklim değişimi, TMMOB İklim Değişimi Sempozyumu, 13-14 Mart 2008, Ankara, Türkiye, s. 27-46. 
Kahya, E., ve Kalayc1, S., 2004. Trend analysis of streamflow in Turkey, Journal of Hydrology, 289, s.128-144.

Kendall, M.G., 1975. Rank correlation methods. Oxford University Press, New York.

Mann, H.B., 1945. Nonparametric tests against trend. Econometrica, 13(3), 245-259, DOI:10.2307/1907187.

Mondal, A., Kundu, S. ve Mukhopadhyay, A., 2012. Rainfall trend analysis by MannKendall test: A case study of NorthEastern part of Cuttack District, Orissa, International Journal of Geology, 2, s.7078.

Okutan, H., Cerit, O. ve Karacan, E., 2004. Küresel İklim Değişiklerinin Çayeli (Rize) Yöresindeki Doğal Afetlerin Oluşumuna Etkilerinin İncelenmesi, I. Ulusal Çevre Kongresi, Sivas, Türkiye, s. 367-377.

Özkoca, T. 2015. Orta Karadeniz bölgesi kıyı illerinin hidrometeorolojik parametrelerinin trend analizi. Yüksek Lisans Tezi, Ondokuz Mayıs Üniversitesi, Fen Bilimleri Enstitüsü.

Partal, T. ve Kahya, E., 2006. Trend analysis in Turkish precipitation data, Hydrological Processes, 20, s.2011-2026.

Pettitt A. N. 1979. A Non-Parametric Approach to the Change-Point Detection, Applied Statistics, Cilt 28, 126-135.

Sen, P.K., 1968. Estimates of the regression coefficient based on Kendall's Tao, Journal of the American Statistical Association, 63, 1379-1389.

Şensoy, S., Demircan, M., ve Alan. İ.,2005. 19712004 Yılları Arası Türkiye İklim İndileri Trendleri, Devlet Meteoroloji İşleri Genel Müdürlüğü.

Tecer, L., Okutan H. ve Cerit O., 2004. İklim Değişimi: 1975- 2001 Periyodunda Rize yağış ve sıcaklık trendlerinin analizi, I. Ulusal Çevre Kongresi, Sivas, Türkiye, s. 355-365.

Tecer, L.H., ve Cerit, O., 2009. Temperature trends and changes in Rize, Turkey, for the period 1975-2007. Clean, 37(2), 150159.

Toros, H., 2012. Spatio-temporal variation of daily extreme temperatures over Turkey, International Journal of Climatology, 32, s.1047-1055.

TUIK, Türkiye İstatistik Kurumu, 2012. Seçilmiş Göstergelerle Samsun 2012, s.14

Türkeş, M., 1989. İklim değişmeleri kuraklık ve çölleşme, D.M.İ. Genel Müdürlüğü Meteoroloji Dergisi, 38, s. 7-24.

Türkeş, M., Sümer, U. M. ve Kılıç, G. 1995. Variations and trends in annual mean air temperatures in Turkey with respect to climatic variability, International Journal of Climatology, 15, s. 557-569.

Türkeş, M., Sümer, U., ve Kılıç, G., 1996. Observed changes in maximum and minimum temperature in Turkey, International Journal of Climatology, 16, s. 463-477.

Türkeş, M., Sümer, U., ve Demir, İ., 2002. Türkiye'nin Günlük Ortalama Maksimum ve Minimum Hava Sicaklıkları İle Sıcaklık Genişliğindeki Eğilimler ve Değiş̧iklikler, 11-13 Nisan Klimatoloji Çalıştayı Bildiriler Kitabı,İzmir, s. 89106.

Türkeş, M., 2007. İklim Değişiliği Nedir? Temel Kavramlar, Nedenleri, Gözlene ve Öngörülen Değişiklikler, I.Türkiye İklim Değişikliği Kongresi Bildiriler Kitabı, s. 38-53, İstanbul.

Yue, S., Zou, S., ve Whittemore, D. 1993. Nonparametric trend analysis of water quality data of rivers in Kansas, Journal of Hydrology 150(1), s. 61-80. 